\title{
The 6-year trajectory of non-traumatic knee symptoms (including patellofemoral pain) in adolescents and young adults in general practice: a study of clinical predictors
}

\author{
M Kastelein, ${ }^{1}$ P A J Luijsterburg, ${ }^{1}$ E M Heintjes, ${ }^{1}$ M van Middelkoop, ${ }^{1}$ \\ J A N Verhaar, ${ }^{2}$ B W Koes, ${ }^{1}$ S M A Bierma-Zeinstra ${ }^{1,2}$
}

${ }^{1}$ Department of General Practice, Erasmus MC University Medical Center, Rotterdam, The Netherlands ${ }^{2}$ Department of Orthopaedics, Erasmus MC University Medical Center, Rotterdam,

The Netherlands

\section{Correspondence to}

Dr P A J Luijsterburg, Department of General Practice, Erasmus MC University Medical Center Rotterdam, PO Box 2040, Rotterdam 3000 CA, The Netherlands; p.luijsterburg@erasmusmc.n

Accepted 11 November 2014 Published Online First 27 November 2014
CrossMark

To cite: Kastelein $\mathrm{M}$ Luiisterburg PAJ,

Heintjes EM, et al. $\mathrm{Br}$ J

Sports Med 2015;49:

400-405.

\section{ABSTRACT}

Aims (1) To assess the 1-year and 6-year courses of nontraumatic knee symptoms in adolescents and young adults presenting in general practice. (2) To identify prognostic factors for persistent knee symptoms at 1-year follow-up. Methods Adolescents and young adults (12-35 years; $n=172$ ) with non-traumatic knee symptoms were included in the cohort study by their general practitioner (GP) and followed for 6 years. Multivariable logistic regression analysis was used to identify prognostic factors for persistent knee symptoms at 1-year follow-up and the area under the receiver operating curve (AUC) was calculated.

Results Persistent knee symptoms in patients receiving a GP diagnosis of unspecified knee symptoms were reported by $41 \%$ of the patients at 1 -year follow-up and by $19 \%$ of the available patients at 6 -year follow-up. Patients receiving a GP diagnosis of patellofemoral pain syndrome had the worse prognosis, with $40 \%$ reporting persistent knee symptoms at 6 -year follow-up.

Prognostic factors associated with persistent knee symptoms at 1-year follow-up were BMI $>25$, low/middle education level, bilateral symptoms and self-reported absence of crepitus of the knee (AUC 0.80) for patients receiving a GP diagnosis of unspecified knee symptoms. For patients receiving a GP diagnosis of patellofemoral pain syndrome, prognostic factors were low/middle education level, poor health, having bilateral symptoms and selfreport of a swollen knee (AUC 0.76).

Conclusions The prognosis of non-traumatic knee symptoms in adolescents and young adults in general practice is not as good as was previously assumed. Several prognostic factors collected at baseline were associated with persistent knee symptoms at follow-up. However, the results should be replicated in another larger study.

\section{INTRODUCTION}

General practitioners (GPs) are frequently consulted by patients with non-traumatic knee symptoms. Non-traumatic knee symptoms in adolescents and young adults account for $20 \%$ of all nontraumatic knee symptoms in general practice and include patellofemoral pain syndrome, ${ }^{1}$ jumper's knee (knee extensor tendinopathy), OsgoodSchlatter disease, bursitis, iliotibial tract friction syndrome and popliteal cysts. ${ }^{2}$ The incidence of these types of symptoms in adolescents and young adults reported in general practice is about 19/ 1000 patients per year. ${ }^{2}$
In comparison with sports medicine, the patellofemoral pain syndrome accounts for up to $25 \%$ of all presented knee symptoms. ${ }^{3}$ To the best of our knowledge, no studies have examined the shortterm and long-term follow-up and prognosis of these symptoms in adolescents and young adults in general practice. ${ }^{5}$

Therefore, this prospective cohort study was performed in general practice to assess the 1-year and 6 -year courses of non-traumatic knee symptoms in adolescents and young adults, and to identify prognostic factors for persistent knee symptoms at 1-year follow-up.

\section{METHODS}

\section{Design}

The present study took place within the research network HONEUR (40 GPs) established by the department of General Practice of Erasmus MC University Medical Centre. It is part of a prospective, observational cohort study $(\mathrm{n}=1068)$ in which consecutive patients visiting their GP with a new episode of knee symptoms were enrolled and initially followed for 1 year. ${ }^{6}$ Owing to the high percentage of persistent knee symptoms at 1-year follow-up, the follow-up period was extended to 6 years.

At baseline, new knee symptoms were defined as episodes of knee pain presented to the GP for the first time. Recurrent symptoms for which the GP was not consulted within the past 3 months were also considered to be new symptoms. Traumatic knee symptoms were defined as knee symptoms caused by a sudden impact or unexpected movement within 1 year before consulting the GP. All other knee symptoms were considered to be nontraumatic knee symptoms.

Patients were eligible for this study if they were aged $12-35$ years and had consulted their GP for non-traumatic knee symptoms (unspecified knee symptoms (ICPC L15) and patellofemoral pain syndrome (ICPC L99.07). Exclusion criteria were knee symptoms that required urgent medical attention (eg, fractures, infection), patients with malignancies, neurological disorders or musculoskeletal diseases (eg, Parkinson's disease, rheumatoid arthritis, amyotrophic lateral sclerosis), as well as patients incapable of understanding the ramifications of study participation. The study protocol was approved by the Medical Ethics committee of the Erasmus MC University Medical Centre. 


\section{Data collection}

Patients filled out a self-report questionnaire at baseline, at the 3, 6 and 9 months follow-up, and at the 1-year and 6-year follow-up.

The baseline and follow-up questionnaire collected data on age, gender, socioeconomic status, knee history of previous injuries or operations, present symptoms, level of daily activities and sports, hindrance and sick leave from daily activities, health-related quality of life and treatments received. Additionally, the 1-year and 6-year follow-up questionnaire collected data on experienced recovery or worsening of the knee symptoms (ie, outcome).

Functional disability and pain were assessed with the Western Ontario and McMaster Universities Osteoarthritis Index (WOMAC) ${ }^{78}$ (assessed at baseline to 1-year follow-up), the Knee Injury Osteoarthritis Outcome Score (KOOS) ${ }^{9}$ (assessed at 6-year follow-up), the Medical Outcomes Study Short Form 36 Health Survey (SF-36), ${ }^{10}{ }^{11}$ the Knee Society Score (KSS) function questions, ${ }^{12}$ the Lysholm Knee Scoring Scale, ${ }^{8} 13$ the Tampa Scale for Kinesophobia ${ }^{14}$ (only assessed at baseline) and the primary care cooperative information project/world organization of family doctors charts ${ }^{15}{ }^{16}$ (only assessed at baseline to 1-year follow-up). The outcome measurement, experienced recovery of knee symptoms, was measured on a seven-point Likert scale. For all scores, except the Lysholm and SF-36, lower scores represent better function/outcome. GPs were asked to note the working diagnosis according to the International Classification of Primary Care (ICPC) in the patient's computerised medical file at first consultation. ${ }^{17}$

\section{Statistical analysis}

Descriptive statistics were used to describe patient characteristics, symptom characteristics, experienced recovery and working diagnosis of the GP. Univariable logistic regression analysis was used to determine which baseline variables from history taking (ie, patient characteristics and symptom characteristics) were associated with persistent knee symptoms at 1-year follow-up, expressed as ORs. The baseline variables chosen for the univariable analysis were based on the literature ${ }^{18}$ and clinical relevance. To enable easy interpretation of prognostic factors in a clinical setting, we chose to dichotomise most variables.

Imputation of missing data was carried out by multiple imputation, creating a total of five imputed databases. ${ }^{19-21}$ The variables showing an univariable association with persistent knee symptoms in at least three out of five imputed databases $(p \leq 0.20)$ were analysed in a multivariable logistic regression model (backward LR method, entry 0.10 , removal 0.15 ). If a variable was selected in at least three out of five imputed databases in the multivariable analysis, it was included in the final model (Enter method) and the area under the receiver operating curve (AUC) was calculated. First, separate models for patient characteristics and symptom characteristics were built. Subsequently, we combined the remaining variables of each domain to build a model of patient and symptom characteristics.

The outcome measurement self-reported perceived recovery was dichotomised into clinical recovery of knee symptoms ('completely recovered' and 'much improved') versus persistent knee symptoms ('slightly improved', 'no change', 'slightly worsened', 'much worsened' and 'worse than ever').

The analyses were performed using SPSS V.21.0 (SPSS Inc, Chicago, Illinois, USA).

\section{RESULTS \\ Study population}

A total of 172 patients receiving a GP diagnosis of nontraumatic knee symptoms were included of whom 98 were diagnosed with 'unspecified knee symptoms' (ICPC L15) and 74 with patellofemoral pain syndrome (ICPC L99.07).

The mean age of the patients receiving a GP diagnosis of unspecified knee symptoms was 25.1 (SD 7.1) years, and 50.0\% were men. In patients with unspecified knee symptoms, a total of 70 patients $(71.4 \%)$ reported that the duration of their knee symptoms was less than 3 months at the time of consultation, 36 patients $(36.7 \%)$ had bilateral knee symptoms, and 48 patients $(49.0 \%)$ reported recurrent knee symptoms.

Regarding the patients receiving a GP diagnosis of patellofemoral pain syndrome, the mean age was 23.7 (SD 7.9) years, $52.7 \%$ were men; 38 patients $(51.4 \%)$ reported that the duration of their knee symptoms was less than 3 months at the time of consultation, 42 patients $(56.8 \%)$ had bilateral knee symptoms, and 42 patients $(56.8 \%)$ reported having recurrent knee symptoms.

The patients available at 1-year and 6-year follow-up showed no significant differences compared with the total study population at baseline regarding age, gender, working diagnosis, knee symptoms, pain score (numerical rating scale (NRS)), Lysholm score and WOMAC index.

Also, the patients available at 6-year follow-up showed no significant difference compared with those available at 1-year follow-up regarding their perceived recovery at 1-year follow-up $(\mathrm{OR}=1.04$, 95\% CI 0.83 to 1.30$)$. Reasons for no longer participating were: lack of time and/or lack of interest $(n=32$; $44 \%$ ), unable to be contacted because of the changed address and/or telephone number $(n=33 ; 45 \%)$, and for 8 patients $(11 \%)$ no reason was available.

\section{Course and prognosis}

Figure 1 presents the 6 -year course of the patients receiving a GP diagnosis of unspecified knee symptoms and the patients receiving a GP diagnosis of patellofemoral pain syndrome regarding mean knee pain severity (measured on an NRS), mean Lysholm knee score and mean WOMAC index. In both groups, the mean pain score, mean Lysholm knee score and mean WOMAC index showed the largest improvement in the first 3 months following consultation with the GP.

Table 1 shows the number of patients with persistent knee symptoms at 1-year and 6-year follow-up for the patients receiving a GP diagnosis of unspecified knee symptoms.

Of the 85 patients available at 1-year follow-up, 35 patients (41\%) reported persistent knee symptoms. Their mean knee pain severity, measured with an NRS, was 3.6 (SD 2.2); their mean Lysholm knee score was 71.6 (SD 17.4) and their mean WOMAC index was 16.1 (SD 16.9). At 6-year follow-up, of the 54 patients, $10(19 \%)$ reported persistent knee symptoms. Compared with baseline, four patients (40\%) reported the same knee symptoms and one patient had another kind of symptom in the same knee.

The outcomes at 1-year and 6-year follow-up regarding the patients receiving a GP diagnosis of patellofemoral pain syndrome are presented in table 2.

Of the 65 patients available at 1-year follow-up, 37 (57\%) reported persistent knee symptoms. Their mean knee pain severity, measured with an NRS, was 3.7 (SD 2.3); their mean Lysholm knee score was 75.3 (SD 15.4) and their mean WOMAC index was 16.2 (SD 15.4). At 6-year follow-up, of the remaining 44 patients, 18 (40\%) reported persistent knee symptoms. Compared with baseline, the kind of knee symptoms had changed to another kind of symptom in the same knee in 3 patients (17\%) and 14 patients $(78 \%)$ reported the same knee symptoms. 
Figure 1 Course of knee symptoms (mean scores) of the patients receiving a diagnosis of unspecified knee symptoms ( $n=98$; closed markers) or patellofemoral pain syndrome $(n=74$; open markers). GP, general practitioner; WOMAC, Western Ontario and McMaster Universities Osteoarthritis Index.

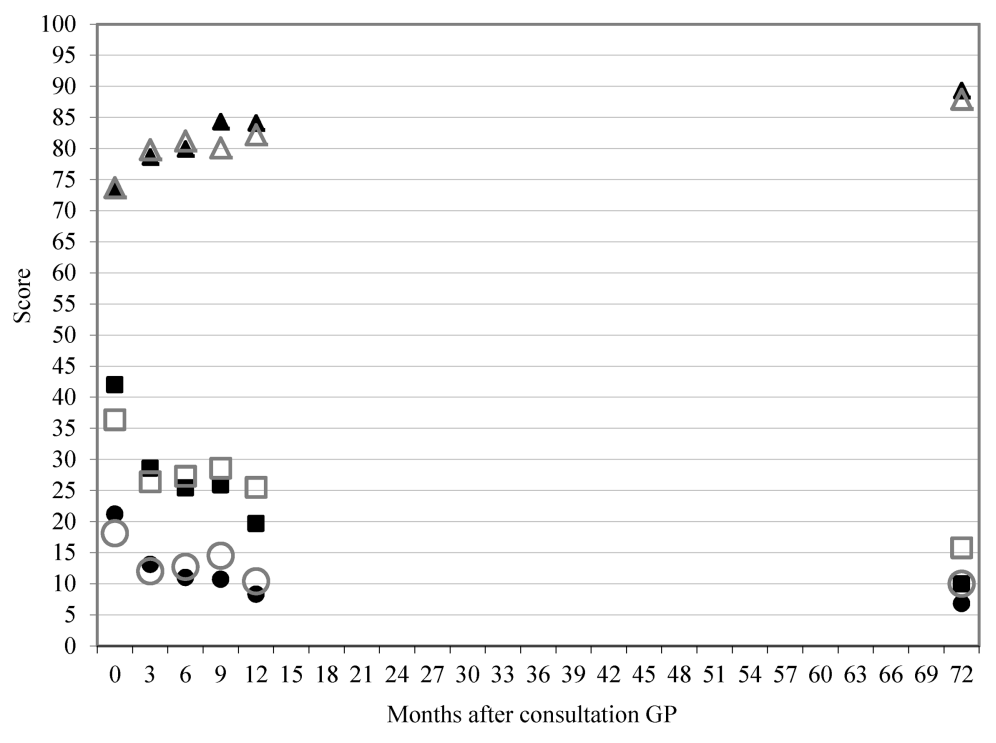

$\Delta$ Lysholm score (0-100): Unspecified Knee Complaints

-Knee pain 0-10NRS (x10): Unspecified Knee Complaints

$\Delta$ Lysholm score (0-100): Patellofemoral Pain Syndrome 口Knee pain 0-10NRS (x10): Patellofemoral Pain Syndrome oWOMAC Index (0-100): Patellofemoral Pain Syndrome

\section{Prognostic factors}

Table 3 presents the univariable and multivariable associations between baseline characteristics and persistent knee symptoms at 1-year follow-up of the patients receiving a GP diagnosis of unspecified knee symptoms.

At 1-year follow-up, in the univariable analysis, the patient characteristics gender, body mass index (BMI) $>25$ and low/ middle education level at baseline were associated with persistent knee symptoms. Of the symptom characteristics, having bilateral symptoms and self-reported absence of crepitus of the knee were associated with persistent knee symptoms at 1-year follow-up.

In the multivariate analysis patients' characteristics, BMI $>25$ and low/middle education level showed an independent association with persistent knee symptoms at 1-year follow-up, with an AUC of 0.75 . From the symptom characteristics, bilateral symptoms and self-reported absence of crepitus of the knee were independently associated with persistent knee symptoms, with an AUC of 0.64 . Adding the symptom characteristics to the patient characteristics, the AUC increased to 0.80 .
The univariable and multivariable associations between baseline characteristics and persistent knee symptoms at 1-year follow-up of the patients receiving a GP diagnosis of patellofemoral pain syndrome are presented in table 4 .

At 1-year follow-up, in the univariable analysis, the patient characteristics $\mathrm{BMI}>25$, low/middle education level at baseline, non-skeletal comorbidity, poor health and participating sports were associated with persistent patellofemoral symptoms. Of the symptom characteristics, having bilateral symptoms, self-report of a swollen knee and locking of the knee were associated with persistent patellofemoral symptoms at 1-year follow-up.

In the multivariate analysis patients' characteristics, low/ middle education level at baseline, non-skeletal comorbidity and reporting poor health showed an independent association with persistent knee symptoms at 1-year follow-up, with an AUC of 0.70. From the symptom characteristics, having bilateral symptoms, self-report of a swollen knee and locking of the knee were independently associated with persistent knee symptoms, with an AUC of 0.70 . Adding the symptom characteristics to the patient characteristics, the AUC increased to 0.76 .

Table 1 Characteristics of patients receiving a GP diagnosis of unspecified knee symptoms at baseline and at 1-year and 6-year follow-up

\begin{tabular}{|c|c|c|c|c|c|}
\hline & \multirow[b]{2}{*}{$\begin{array}{l}\text { Baseline } \\
\mathrm{n}=98\end{array}$} & \multicolumn{2}{|l|}{$\begin{array}{l}\text { 1-Year follow-up } \\
n=85\end{array}$} & \multicolumn{2}{|l|}{$\begin{array}{l}\text { 6-Year follow-up } \\
n=54\end{array}$} \\
\hline & & $\begin{array}{l}\text { Persistent symptoms } \\
\mathrm{n}=35\end{array}$ & $\begin{array}{l}\text { Recovered } \\
n=50\end{array}$ & $\begin{array}{l}\text { Persistent symptoms } \\
n=10\end{array}$ & $\begin{array}{l}\text { Recovered } \\
\mathrm{n}=44\end{array}$ \\
\hline \multicolumn{6}{|l|}{ Measures of severity } \\
\hline Knee pain NRS 0-10, mean (SD) & $4.3(2.0)$ & $3.6(2.2)$ & $0.7(1.3)$ & $2.8(1.4)$ & $0.5(1.1)$ \\
\hline Lysholm score 0-100, mean (SD) & $73.7(14.6)$ & $71.6(17.4)$ & $93.6(7.7)$ & $72.6(17.9)$ & $74.9(14.0)$ \\
\hline WOMAC index 0-100, mean (SD) & $21.2(17.3)$ & $16.1(16.9)$ & $2.3(3.6)$ & $19.6(11.1)$ & $3.7(8.4)$ \\
\hline WOMAC pain $0-100$, mean (SD) & $26.8(18.7)$ & $18.4(17.2)$ & $2.9(5.2)$ & $28.8(19.2)$ & $4.3(8.9)$ \\
\hline WOMAC stiffness 0-100, mean (SD) & $19.8(22.3)$ & $19.9(23.7)$ & $4.3(9.9)$ & $42.2(29.8)$ & $5.0(13.0)$ \\
\hline WOMAC function 0-100, mean (SD) & $22.0(18.8)$ & $15.0(17.4)$ & $1.8(3.1)$ & $15.8(10.7)$ & $3.4(8.1)$ \\
\hline \multicolumn{6}{|c|}{ Nature/type of knee symptoms compared with baseline } \\
\hline Other symptoms, n (\%) & - & - & - & $1(10)$ & $4(9)$ \\
\hline Same symptoms, n (\%) & - & - & - & $4(40)$ & $5(11)$ \\
\hline Same and other symptoms, $\mathrm{n}(\%)$ & - & - & - & $3(30)$ & $0(0)$ \\
\hline
\end{tabular}


Table 2 Characteristics of patients receiving a GP diagnosis of patellofemoral pain syndrome at baseline and at 1-year and 6-year follow-up

\begin{tabular}{|c|c|c|c|c|c|}
\hline & \multirow[b]{2}{*}{$\begin{array}{l}\text { Baseline } \\
\mathrm{n}=74\end{array}$} & \multicolumn{2}{|l|}{$\begin{array}{l}\text { 1-Year follow-up } \\
n=65\end{array}$} & \multicolumn{2}{|l|}{$\begin{array}{l}\text { 6-Year follow-up } \\
n=45\end{array}$} \\
\hline & & $\begin{array}{l}\text { Persistent symptoms } \\
\mathrm{n}=37\end{array}$ & $\begin{array}{l}\text { Recovered } \\
\mathrm{n}=28\end{array}$ & $\begin{array}{l}\text { Persistent symptoms } \\
n=18\end{array}$ & $\begin{array}{l}\text { Recovered } \\
\mathrm{n}=27\end{array}$ \\
\hline \multicolumn{6}{|l|}{ Measures of severity } \\
\hline Knee pain NRS 0-10, mean (SD) & $3.6(2.3)$ & $3.7(2.3)$ & $1.1(1.8)$ & $2.7(2.0)$ & $0.7(1.7)$ \\
\hline Lysholm score 0-100, mean (SD) & $73.7(14.0)$ & $75.3(15.4)$ & $91.4(14.2)$ & $69.3(12.5)$ & $77.8(13.3)$ \\
\hline WOMAC index 0-100, mean (SD) & $18.1(15.4)$ & $16.2(15.4)$ & $2.7(4.9)$ & $18.7(15.6)$ & $2.9(7.3)$ \\
\hline WOMAC pain $0-100$, mean (SD) & $22.4(16.9)$ & $18.3(17.0)$ & $3.5(7.1)$ & $23.5(19.1)$ & $3.4(10.3)$ \\
\hline WOMAC stiffness $0-100$, mean (SD) & $23.6(22.3)$ & $17.6(18.7)$ & $5.7(12.8)$ & $27.9(20.5)$ & $6.3(11.4)$ \\
\hline WOMAC function 0-100, mean (SD) & $18.4(15.8)$ & $15.4(16.1)$ & $2.1(4.5)$ & $16.2(15.6)$ & $2.4(6.3)$ \\
\hline \multicolumn{6}{|c|}{ Nature/type of knee symptoms compared with baseline } \\
\hline Other symptoms, n (\%) & - & - & - & $3(17)$ & $4(15)$ \\
\hline Same symptoms, n (\%) & - & - & - & $14(78)$ & $2(7)$ \\
\hline Same and other symptoms, $\mathrm{n}(\%)$ & - & - & - & $0(0)$ & $0(0)$ \\
\hline
\end{tabular}

GP, general practitioner; WOMAC, Western Ontario and McMaster Universities Osteoarthritis Index.

\section{DISCUSSION}

At 1-year follow-up, a surprisingly high percentage of $41 \%$ of patients receiving a GP diagnosis of unspecified knee symptoms reported persistent knee symptoms, and an even higher percentage of persistent knee symptom for patients receiving a GP diagnosis of patellofemoral pain syndrome

Table 3 Univariable and multivariable association between baseline characteristics and persistent knee symptoms at 1-year follow-up of the patients receiving a GP diagnosis of unspecified knee symptoms

\begin{tabular}{|c|c|c|c|c|c|}
\hline \multirow[b]{2}{*}{ Variable } & \multicolumn{2}{|c|}{ Univariate 1 year $(n=98)$} & \multicolumn{3}{|c|}{ Multivariate 1 year $(n=98)$} \\
\hline & $\begin{array}{l}\text { Pooled } \\
\text { OR }(95 \% \mathrm{Cl})\end{array}$ & $\begin{array}{l}\text { Pooled } \\
\text { Sig }\end{array}$ & $\begin{array}{l}\text { Pooled } \\
\text { OR }(95 \% \mathrm{Cl})\end{array}$ & $\begin{array}{l}\text { Pooled } \\
\text { Sig }\end{array}$ & AUC \\
\hline Patient characteristics & & & & & 0.75 \\
\hline Age in years & $1.0(1.0$ to 1.1$)$ & 0.33 & & & \\
\hline Gender (men vs women) & $0.5(0.2$ to 1.3$)$ & $0.17^{*}$ & & & \\
\hline Body mass index $>25$ & 2.5 (1.0 to 6.2$)$ & $0.04^{*}$ & 3.2 (1.2 to 8.6$)$ & 0.23 & \\
\hline Low/middle education level & $4.7(1.7$ to 13.0$)$ & $0.002^{*}$ & $5.6(1.9$ to 16.2$)$ & 0.001 & \\
\hline Comorbidity skeletal system & $1.0(0.4$ to 2.8$)$ & 0.96 & & & \\
\hline Non-skeletal comorbidity & $1.0(0.3$ to 3.2$)$ & 0.97 & & & \\
\hline Poor health (COOP-WONCA) & $1.5(0.3$ to 6.4$)$ & 0.60 & & & \\
\hline Sports & $1.1(0.4$ to 2.9$)$ & 0.90 & & & \\
\hline Symptom characteristics & & & & & 0.64 \\
\hline Duration $>3$ months & $1.3(0.5$ to 3.5$)$ & 0.60 & & & \\
\hline Recurrent symptoms & $1.3(0.5$ to 3.0$)$ & 0.60 & & & \\
\hline Bilateral symptoms & 2.1 (0.9 to 5.2$)$ & $0.11^{*}$ & 2.2 (0.9 to 5.6$)$ & 0.09 & \\
\hline Pain (11-point scale) & $1.0(0.8$ to 1.2$)$ & 0.90 & & & \\
\hline Self-report warm knee & 1.7 (0.7 to 4.4$)$ & 0.26 & & & \\
\hline Self-report swollen knee & 2.8 (1.8 to 4.5$)$ & 0.23 & & & \\
\hline Self-report crepitus knee & $0.4(0.1$ to 1.3$)$ & $0.12^{*}$ & $0.4(0.1$ to 1.2$)$ & 0.10 & \\
\hline Locking of the knee (Lysholm) & 1.1 (0.3 to 3.6$)$ & 0.85 & & & \\
\hline Instability of the knee (Lysholm) & $1.6(0.6$ to 4.0$)$ & 0.32 & & & \\
\hline History of knee symptoms & $0.7(0.3$ to 1.9$)$ & 0.53 & & & \\
\hline WOMAC function & 1.0 (1.0 to 1.2$)$ & 0.63 & & & \\
\hline WOMAC pain & $1.0(1.0$ to 1.1$)$ & 0.67 & & & \\
\hline WOMAC stiffness & $1.0(1.0$ to 1.1$)$ & 0.54 & & & \\
\hline Patient and symptom characteristics & & & & & 0.80 \\
\hline Body mass index $>25$ & & & 3.7 (1.3 to 10.4$)$ & 0.02 & \\
\hline Low/middle education level & & & $6.0(2.0$ to 18.1$)$ & 0.002 & \\
\hline Bilateral symptoms & & & 2.6 (0.9 to 7.4$)$ & 0.07 & \\
\hline Self-report crepitus knee & & & $0.3(0.1$ to 1.2$)$ & 0.09 & \\
\hline
\end{tabular}


Table 4 Univariable and multivariable association between baseline characteristics and persistent knee symptoms at 1-year follow-up of the patients receiving a GP diagnosis of patellofemoral pain syndrome

\begin{tabular}{|c|c|c|c|c|c|}
\hline \multirow[b]{2}{*}{ Variable } & \multicolumn{2}{|c|}{ Univariate 1 year $(n=74)$} & \multicolumn{3}{|c|}{ Multivariate 1 year $(n=74)$} \\
\hline & $\begin{array}{l}\text { Pooled } \\
\text { OR }(95 \% \mathrm{Cl})\end{array}$ & $\begin{array}{l}\text { Pooled } \\
\text { Sig }\end{array}$ & $\begin{array}{l}\text { Pooled } \\
\text { OR }(95 \% \mathrm{CI})\end{array}$ & $\begin{array}{l}\text { Pooled } \\
\text { Sig }\end{array}$ & AUC \\
\hline Patient characteristics & & & & & 0.70 \\
\hline Age in years & $1.0(0.9$ to 1.1$)$ & 0.98 & & & \\
\hline Gender (men vs women) & 1.2 (0.5 to 3.3 ) & 0.69 & & & \\
\hline Body mass index $>25$ & $2.3(0.7$ to 7.7$)$ & $0.19^{*}$ & & & \\
\hline Low/middle education level & $2.4(0.8$ to 6.8$)$ & $0.11^{*}$ & $2.5(0.8$ to 7.8$)$ & 0.12 & \\
\hline Comorbidity skeletal system & $0.8(0.3$ to 2.5$)$ & 0.75 & & & \\
\hline Non-skeletal comorbidity & $3.5(0.7$ to 17.9$)$ & $0.13^{*}$ & $3.4(0.6$ to 19.7$)$ & 0.17 & \\
\hline Poor health (COOP-WONCA) & $2.7(0.7$ to 11.0$)$ & $0.17^{*}$ & $3.7(0.9$ to 15.5$)$ & 0.09 & \\
\hline Sports & $0.4(.01$ to 1.5$)$ & $0.18^{*}$ & & & \\
\hline Symptom characteristics & & & & & 0.70 \\
\hline Duration $>3$ months & $1.0(0.4$ to 2.8$)$ & 0.95 & & & \\
\hline Recurrent symptoms & $0.6(0.2$ to 1.7$)$ & 0.35 & & & \\
\hline Bilateral symptoms & $2.0(0.7$ to 5.6$)$ & $0.18^{*}$ & $2.6(0.9$ to 8.1$)$ & 0.09 & \\
\hline Pain (11-point scale) & $1.0(0.8$ to 1.2$)$ & 0.88 & & & \\
\hline Self-report warm knee & $1.3(0.4$ to 4.1$)$ & 0.63 & & & \\
\hline Self-report swollen knee & 2.6 (0.8 to 8.4$)$ & $0.12^{*}$ & 2.5 (0.7 to 9.2$)$ & 0.17 & \\
\hline Self-report crepitus knee & $1.0(0.1$ to 6.2$)$ & 0.95 & & & \\
\hline Locking of the knee (Lysholm) & $4.2(0.9$ to 20.3$)$ & $0.07^{*}$ & $3.9(0.7$ to 20.1$)$ & 0.11 & \\
\hline Instability of the knee (Lysholm) & 1.2 (0.4 to 3.2$)$ & 0.78 & & & \\
\hline History of knee symptoms & $1.9(0.7$ to 5.4$)$ & 0.23 & & & \\
\hline WOMAC function & $1.0(0.9$ to 1.0$)$ & 0.21 & & & \\
\hline WOMAC pain & $1.0(0.9$ to 1.0$)$ & 0.24 & & & \\
\hline WOMAC stiffness & $1.0(0.9$ to 1.0$)$ & 0.31 & & & \\
\hline Patient and symptom characteristics & & & & & 0.76 \\
\hline Low/middle education level & & & $4.5(1.2$ to 16.4$)$ & 0.02 & \\
\hline Poor health (COOP-WONCA) & & & 4.7 (0.9 to 23.8$)$ & 0.06 & \\
\hline Bilateral symptoms & & & $3.4(1.0$ to 11.8$)$ & 0.05 & \\
\hline Self-report swollen knee & & & 4.9 (1.2 to 20.2$)$ & 0.03 & \\
\hline
\end{tabular}

(57\%). At 6-year follow-up, $19 \%$ of the patients with unspecified knee symptoms at baseline and $40 \%$ of the patients with patellofemoral pain syndrome still reported persistent knee symptoms. In this study, the finding that patients receiving a GP diagnosis of patellofemoral pain syndrome had the worst prognosis is in accordance with the (few) reports available from secondary care..$^{22-27}$

Regarding the patients receiving a GP diagnosis of unspecified knee symptoms at baseline, prognostic factors associated with persistent knee symptoms at 1-year follow-up were BMI $>25$, low/middle education level, bilateral symptoms and self-reported absence of crepitus of the knee. Regarding the patients receiving a GP diagnosis of patellofemoral pain syndrome at baseline, associated with persistent knee symptoms at 1-year follow-up were low/middle education level, poor health, having bilateral symptoms and self-report of a swollen knee. Findings from a physical examination were not included in the analyses and could reveal other risk factors for persistent knee symptoms. ${ }^{28}$

Our study is the first to report on prognostic factors in adolescents and young adults with non-traumatic knee symptoms in general practice.

Most of the prognostic factors revealed in this study (especially the patient and symptom characteristics) are also reported in other studies on prognostic factors in adults with knee pain, ${ }^{29-32}$ in patients with other musculoskeletal disorders ${ }^{18} 33$ or in patients with patellofemoral pain syndrome. ${ }^{24} 34$

\section{Limitations}

One limitation of this study is that a relatively large percentage was lost to follow-up, especially at 6-year follow-up (42\%). For example, some people changed addresses and some lost interest in the study. However, the patients available at 1-year and 6-year follow-up showed no major differences in characteristics observed at baseline.

We decided to perform univariable regression analysis with a relatively large $p$ value of 0.20 to determine which factors to test in multivariable analysis; this was due to the difficulty in choosing possible prognostic factors in view of the lack of research in this field. Consequently, in a relative small patient sample, we tested a large number of prognostic factors in the univariable analysis. Therefore, it is important that our findings should be replicated in other larger patient samples and that for now the results should be interpreted with caution. Also, in this study, there is a lack of information on treatment during the follow-up period which could have influenced the outcome. However, the number of patients receiving surgery was low $(n=7)$ at 6-year follow-up. 


\section{Implications for clinical practice and future research}

For adolescents and young adults with non-traumatic knee symptoms, GPs should consider those with patellofemoral pain syndrome as a separate group, because their prognosis is worse than that for the unspecified knee symptoms. ${ }^{1}$ In particular, we need to elucidate the mechanisms behind patellofemoral pain syndrome. $^{35-38}$

\section{CONCLUSIONS}

The prognosis of non-traumatic knee symptoms in adolescents and young adults in general practice is not good. Various baseline prognostic factors seem to be associated with persistent knee symptoms at 1-year follow-up but should be replicated in another larger study.

The prognosis of patients receiving a GP diagnosis of patellofemoral pain syndrome seemed worse than that for patients receiving a GP diagnosis of unspecified knee symptoms, with $40 \%$ of the former reporting persistent symptoms at 6-year follow-up.

\section{What are the new findings?}

The prognosis for patients who present in general practice with non-traumatic knee symptoms in adolescents and young adults is not as good as was previously assumed.

\section{How might it impact on clinical practice in the near future?}

- General practitioners should consider patients with patellofemoral pain syndrome as a separate group, because their prognosis is worse than that of patients with unspecified knee symptoms.

- Clinicians should remain alert to discoveries relating to the mechanisms behind patellofemoral pain syndrome (fast knowledge translation).

Contributors JANV, BWK and SMAB-Z contributed substantially to the conception and design of the study. MK and EMH were involved in the acquisition of data. MK, PAJL, MvM and SMAB-Z were involved in the analysis and interpretation of data and in drafting the manuscript. All authors revised the draft manuscript critically and have read and approved the final manuscript.

Funding The research network Honeur was financially supported by the health insurance companies TRIAS, Zilveren Kruis Achmea and OZ, and partly funded by a programme grant of the Dutch Arthritis Foundation.

\section{Competing interests None.}

Patient consent Obtained.

Ethics approval Ethics Committee Erasmus MC, Rotterdam, Netherlands.

Provenance and peer review Not commissioned; externally peer reviewed.

Data sharing statement The data are anonymised and the risk of identification is low. Data from the trial may be available from the corresponding author at p.luijsterburg@erasmusmc.nl subject to agreement about the use of the data.

\section{REFERENCES}

1 Witvrouw E, Callaghan MJ, Stefanik JJ, et al. Patellofemoral pain: consensus statement from the 3rd International Patellofemoral Pain Research Retreat held in Vancouver, September 2013. Br J Sports Med 2014;48:411-14.

2 van der Linden MW, Westert GP, de Bakker DH, et al. Second national Dutch study: complaints and disorders in general practice (in Dutch). Netherlands institute for health services research NIVEL 2004:1-136.

3 Dutton RA, Khadavi MJ, Fredericson M. Update on rehabilitation of patellofemoral pain. Curr Sports Med Rep 2014;13:172-8.
4 Petersen W, Ellermann A, Gösele-Koppenburg A, et al. Patellofemoral pain syndrome. Knee Surg Sports Traumatol Arthrosc 2014;22:2264-74.

5 Breedveldt Boer HP, Klaassen WRC, Spinnewijn WEM, et al. NHG-guideline: non-traumatic knee disorders in children and adolescents (in Dutch). Huisarts en Wetenschap 2009;52:332-41.

6 Heintjes EM, Berger MY, Koes BW, et al. Knee disorders in primary care: design and patient selection of the HONEUR knee cohort. BMC Musculoskelet Disord 2005;6:45.

7 Bellamy N, Buchanan WW, Goldsmith $\mathrm{CH}$, et al. Validation study of WOMAC: a health status instrument for measuring clinically important patient relevant outcomes to antirheumatic drug therapy in patients with osteoarthritis of the hip or knee. J Rheumatol 1988;15:1833-40.

8 Heintjes EM, Bierma-Zeinstra SM, Berger MY, et al. Lysholm scale and WOMAC index were responsive in prospective cohort of young general practice patients. J Clin Epidemiol 2008;61:481-8.

9 Roos EM, Roos HP, Lohmander LS, et al. Knee Injury and Osteoarthritis Outcome Score (KOOS) - development of a self-administered outcome measure. J Orthop Sports Phys Ther 1998;28:88-96.

10 Aaronson NK, Muller M, Cohen PD, et al. Translation, validation, and norming of the Dutch language version of the SF-36 Health Survey in community and chronic disease populations. J Clin Epidemiol 1998;51:1055-68.

11 Ware JE Jr, Sherbourne CD. The MOS 36-item short-form health survey (SF-36). I. Conceptual framework and item selection. Med Care 1992;30:473-83.

12 Insall JN, Dorr LD, Scott RD, et al. Rationale of the Knee Society clinical rating system. Clin Orthop Relat Res 1989;248:13-14.

13 Tegner Y, Lysholm J. Rating systems in the evaluation of knee ligament injuries. Clin Orthop Relat Res 1985;198:43-9.

14 Swinkels-Meewisse EJ, Swinkels RA, Verbeek AL, et al. Psychometric properties of the Tampa Scale for kinesiophobia and the fear-avoidance beliefs questionnaire in acute low back pain. Man Ther 2003;8:29-36.

15 Nelson E, Wasson J, Kirk J, et al. Assessment of function in routine clinical practice: description of the COOP Chart method and preliminary findings. J Chronic Dis 1987;40(Suppl 1):55S-69S

16 Van Weel C. Functional status in primary care: COOP/WONCA charts. Disabil Rehabil 1993;15:96-101.

17 Lamberts H, Wood M. International classification of primary care. Oxford: Oxford University Press, 1993.

18 Mallen CD, Peat G, Thomas E, et al. Prognostic factors for musculoskeletal pain in primary care: a systematic review. Br J Gen Pract 2007;57:655-61.

19 Donders AR, van der Heijden GJ, Stijnen T, et al. Review: a gentle introduction to imputation of missing values. J Clin Epidemiol 2006;59:1087-91.

20 Moons KG, Donders RA, Stijnen T, et al. Using the outcome for imputation of missing predictor values was preferred. J Clin Epidemiol 2006;59:1092-101.

21 van der Heijden GJ, Donders AR, Stijnen T, et al. Imputation of missing values is superior to complete case analysis and the missing-indicator method in multivariable diagnostic research: a clinical example. J Clin Epidemiol 2006;59:1102-9.

22 Blond L, Hansen L. Patellofemoral pain syndrome in athletes: a 5.7-year retrospective follow-up study of 250 athletes. Acta Orthop Belg 1998;64:393-400.

23 Kannus P, Natri A, Paakkala T, et al. An outcome study of chronic patellofemoral pain syndrome. Seven-year follow-up of patients in a randomized, controlled trial. J Bone Joint Surg Am 1999;81:355-63.

24 Collins NJ, Crossley KM, Darnell R, et al. Predictors of short and long term outcome in patellofemoral pain syndrome: a prospective longitudinal study. BMC Musculoskelet Disord 2010;11:11.

25 van Linschoten R, van Middelkoop M, Berger MY, et al. Supervised exercise therapy versus usual care for patellofemoral pain syndrome: an open label randomised controlled trial. BMJ 2009;339:b4074.

26 Clark DI, Downing N, Mitchell J, et al. Physiotherapy for anterior knee pain: a randomised controlled trial. Ann Rheum Dis 2000;59:700-4.

27 Witvrouw E, Danneels L, Van Tiggelen D, et al. Open versus closed kinetic chain exercises in patellofemoral pain: a 5-year prospective randomized study. Am J Sports Med 2004;32:1122-30.

28 Rathleff MS, Rathleff CR, Crossley KM, et al. Is hip strength a risk factor for patellofemoral pain? A systematic review and meta-analysis. Br J Sports Med 2014;48:1088.

29 Belo JN, Berger MY, Koes BW, et al. Prognostic factors in adults with knee pain in general practice. Arthritis Rheum 2009;61:143-51.

30 Jinks $C$, Jordan KP, Blagojevic $M$, et al. Predictors of onset and progression of knee pain in adults living in the community. A prospective study. Rheumatology (Oxford) 2008;47:368-74.

31 Thomas E, Peat G, Mallen C, et al. Predicting the course of functional limitation among older adults with knee pain: do local signs, symptoms and radiographs add anything to general indicators? Ann Rheum Dis 2008;67:1390-8.

32 van der Waal JM, Bot SD, Terwee CB, et al. Course and prognosis of knee complaints in general practice. Arthritis Rheum 2005;53:920-30. 
33 Khatun M, Ahlgren C, Hammarstrom A. The influence of factors identified in adolescence and early adulthood on social class inequities of musculoskeletal disorders at age 30: a prospective population-based cohort study. Int J Epidemiol 2004;33:1353-60.

34 Natri $A$, Kannus $P$, Jarvinen $M$. Which factors predict the long-term outcome in chronic patellofemoral pain syndrome? A 7-yr prospective follow-up study. Med Sci Sports Exerc 1998;30:1572-7.
35 Dye SF. The pathophysiology of patellofemoral pain: a tissue homeostasis perspective. Clin Orthop Relat Res 2005;436:100-10.

36 Earl JE, Vetter CS. Patellofemoral pain. Phys Med Rehabil Clin N Am 2007;18:439-58, viii.

37 Fulkerson JP. Diagnosis and treatment of patients with patellofemoral pain. Am J Sports Med 2002;30:447-56.

38 Thomee R, Augustsson J, Karlsson J. Patellofemoral pain syndrome: a review of current issues. Sports Med 1999;28:245-62. 